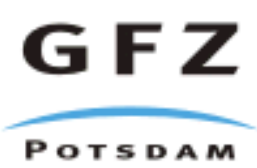

Originally published as:

Steigenberger, P., Tesmer, V., Krügel, M., Thaller, D., Schmid, R., Vey, S., Rothacher, M. (2007): Comparisons of homogeneously reprocessed GPS and VLBI long time-series of troposhere zenith delays and gradients. - Journal of Geodesy, 81, 6-8, 503-514

DOI: 10.1007/s00190-006-0124-y. 
Peter Steigenberger • Volker Tesmer · Manuela Krügel ·

Daniela Thaller · Ralf Schmid · Sibylle Vey · Markus Rothacher

\title{
Comparisons of Homogeneously Reprocessed GPS and VLBI Long Time-series of Troposphere Zenith Delays and Gradients
}

\begin{abstract}
Troposphere parameters estimated from space-geodetic techniques, like the Global Positioning System (GPS) or Very Long Baseline Interferometry (VLBI), can be used to monitor the atmospheric water vapor content. Although the troposphere can only be monitored at discrete locations, the distribution of the instruments, at least the GPS antennas, can be assumed to be quasi-global. Critical in the data analysis are systematic effects within each single technique that significantly degrade the accuracy and especially the long-term stability of the zenith delay determination. In this paper, consistent time-series of troposphere zenith delays and gradients from homogeneously reprocessed GPS and VLBI solutions are compared for a time period of 11 years. The homogeneity of these completely reprocessed time-series is essential to avoid misinterpretations due to individual model changes. Co-located sites are used to investigate systematic effects and the long-term behavior of the two space-geodetic techniques. Both techniques show common signals in the troposphere parameters at a very high level of precision. The biases between the troposphere zenith delays are at the level of a few millimeters. On the other hand, long-term trends significantly differ for the two techniques, preventing climatological interpretations at present. Tests assume these differences to be due to mathematical artifacts such as different sampling rates and unmodeled semi-annual signals with varying amplitudes.
\end{abstract}

Keywords Troposphere zenith delay · troposphere gradients · Global Positioning System · Very Long Baseline Interferometry

P. Steigenberger, D. Thaller

Forschungseinrichtung Satellitengeodäsie, Technische Universität München, D-80290 München, Germany

Present address:

Department of Geodesy and Remote Sensing, GeoForschungsZentrum Potsdam, Telegrafenberg A17, D-14473 Potsdam, Germany

Tel.: +49-331-2881133

Fax: +49-331-2881759

E-mail: steigenberger@gfz-potsdam.de,thaller@gfz-potsdam.de

V. Tesmer, M. Krügel

Deutsches Geodätisches Forschungsinstitut, Alfons-Goppel-Straße 11, D-80539 München, Germany

E-mail: tesmer@dgfi.badw.de,kruegel@dgfi.badw.de

\section{R. Schmid}

Institut für Astronomische und Physikalische Geodäsie, Technische Universität München, D-80290 München, Germany

E-mail: schmid@bv.tum.de

S. Vey

Institut für Planetare Geodäsie, Technische Universität Dresden, D-01062 Dresden, Germany

E-mail: vey@ipg.geo.tu-dresden.de

M. Rothacher

Department of Geodesy and Remote Sensing, GeoForschungsZentrum Potsdam, Telegrafenberg A17, D-14473 Potsdam, Germany E-mail: rothacher@gfz-potsdam.de 


\section{Introduction}

Comparisons between GPS- and VLBI-derived troposphere zenith delays have been performed by a number of authors (e.g. Behrend et al 2000; Gradinarsky et al 2000; Niell et al 2001; Pacione et al 2002; Snajdrova et al 2005). The number of long-term studies is much smaller: Gradinarsky et al (2002) analyzed more than seven years of continuous GPS observations from the Swedish permanent network and determined an increase of the integrated water vapor of 0.1-0.2 mm/y. Haas et al (2003) compared the precipitable water vapor for Onsala derived from GPS and VLBI as well as from radiosondes and a water vapor radiometer. Boehm et al (2003) determined a trend in the estimated VLBI zenith wet delay of $+0.7 \mathrm{~mm} / \mathrm{y}$ for Wettzell, Germany. Troposphere gradient time-series estimated by the Center for Orbit Determination in Europe (CODE) analysis center (AC) of the International GNSS Service (IGS) were analyzed by Meindl et al (2004), whereas Boehm et al (2001) compared troposphere gradients from two different GPS solutions with their own VLBI solution for four 24-hour sessions. In the latter study, even the differences of the two GPS solutions were remarkably high (1-2 mm), probably due to differences in the individual software packages concerning modeling and parameterization.

Regional and local GPS solutions (like most of those mentioned above) are usually based on precise (final) orbits provided by the IGS. These orbits are a combination of near real-time analyses of several ACs and therefore affected by changes in the modeling and processing of the individual ACs as well as by changes in the definition of the geodetic datum. These inconsistencies, however, propagate into the estimated troposphere parameters. Of course, time-series of troposphere parameters stemming from global solutions including the orbit determination are directly affected by the changes mentioned above, if the observations of such solutions are not reprocessed in a homogeneous way.

To avoid any degradation from that side, the GPS solution presented in this paper is a completely and homogeneously reprocessed solution starting with raw RINEX (Receiver INdependent EXchange format) observation data. All relevant parameters (e.g. station coordinates, satellite orbits, Earth rotation parameters (ERPs) and, of course, troposphere parameters) were estimated consistently (see Sect. 2), and IGS orbits were used as a priori information only. Due to the huge amount of data, the processing time for a solution covering 11 years of data was about two months on 12 nodes of a Linux-Cluster. In case of VLBI, despite having more than 20 years of good observational data available, the number of observations is much smaller and thus, it is much easier to perform a complete reprocessing (1-2 days on a single computer). Moreover, the celestial frame for VLBI consists of quasar coordinates instead of dynamic orbits, also reducing the VLBI processing load compared to GPS.

A critical issue when comparing common parameters from GPS and VLBI are systematic effects between the two techniques and the corresponding software packages. In the previous studies mentioned above each software package used its own standards and parameterizations. In the framework of recent combination studies using GPS and VLBI data collected during the CONT02 campaign (Krügel et al 2004; Thaller et al 2006), an intensive homogenization concerning modeling (solid Earth tides, pole tide, ocean loading, high-frequency ERP model, nutation and precession model, troposphere a priori model and mapping functions) and parameterization (constant offsets for station coordinates, continuous piece-wise linear functions for troposphere zenith delays and ERPs) has been performed as regards the two software packages used: Bernese GPS Software (Hugentobler et al 2006) and OCCAM (Titov et al 2004). This is essential in order to avoid misinterpretations due to differences in modeling and parameterization.

In Section 2, the GPS and VLBI solutions are briefly described together with the modeling of the troposphere. In Section 3, the zenith total delays for stations with more than one GPS site are used to compare the consistency of our reprocessed GPS solution with the IGS troposphere parameters. GPS/VLBI co-locations are used to compare the troposphere zenith wet delays and long-term trends, as well as to identify GPS tracking problems. The troposphere gradients of GPS/GPS and GPS/VLBI co-locations are discussed in Section 4.

\section{GPS and VLBI processing}

The station network used here contains, among others, 36 GPS antennas that are installed in the vicinity of 27 VLBI stations. When excluding the co-location with the largest distance between the GPS and the VLBI reference point (Urumqi with a height difference of $1174 \mathrm{~m}$ and a horizontal distance of more than $50 \mathrm{~km}$ ), the height differences vary from $1.5 \mathrm{~m}$ to $400 \mathrm{~m}$ and the horizontal distances from $6 \mathrm{~m}$ to $8 \mathrm{~km}$ with median values of $9 \mathrm{~m}$ and $87 \mathrm{~m}$, respectively. The GPS and VLBI stations with more than 500 troposphere parameters at common epochs are listed in Table 1, together with the corresponding observation periods.

The GPS processing, covering the time interval from January 1, 1994, to December 31, 2004 (4017 days), was performed by the Universities of Technology in Dresden and Munich using the Bernese GPS Software 5.0 
Table 1 Comparison of GPS and VLBI ZWD estimates (GPS ZWD estimates have been interpolated to 1-hourly values). The bias (GPS-VLBI) has been corrected for the theoretical bias due to the height difference between the GPS antenna and the VLBI telescope.

\begin{tabular}{|c|c|c|c|c|c|c|c|c|c|c|}
\hline \multirow{3}{*}{$\begin{array}{l}\text { Station } \\
\text { Algonquin Park }\end{array}$} & \multirow{3}{*}{$\begin{array}{l}\text { VLBI } \\
\text { ALGOPARK }\end{array}$} & \multirow{2}{*}{\multicolumn{2}{|c|}{ Observation Period }} & \multirow{3}{*}{$\begin{array}{l}\text { GPS } \\
\text { ALGO }\end{array}$} & \multirow{2}{*}{\multicolumn{2}{|c|}{ Observation Period }} & \multirow{3}{*}{$\begin{array}{l}\text { \# Par. } \\
10000\end{array}$} & \multirow{3}{*}{$\begin{array}{r}\begin{array}{r}\text { Bias } \\
{[\mathrm{mm}]}\end{array} \\
-0.5\end{array}$} & \multirow{3}{*}{ 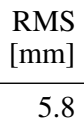 } & \multirow{3}{*}{$\begin{array}{l}\text { Corr. } \\
0.995\end{array}$} \\
\hline & & & & & & & & & & \\
\hline & & May 1994 & Dec 2004 & & Jan 1994 & Dec 2004 & & & & \\
\hline Fairbanks & GILCREEK & Jan 1994 & Dec 2004 & FAIR & Jan 1994 & Dec 2004 & 19902 & -4.5 & 5.9 & 0.993 \\
\hline Fortaleza & FORTLEZA & Jan 1994 & Dec 2004 & FORT & Jan 1994 & Dec 2004 & 11784 & +7.2 & 14.1 & 0.962 \\
\hline \multirow[t]{3}{*}{ Hartebeesthoek } & HARTRAO & Jan 1994 & Dec 2004 & HARK & Jun 1997 & Aug 2000 & 1983 & -9.2 & 8.9 & 0.988 \\
\hline & & & & HART & Jan 1994 & Jun 1997 & 1310 & -9.2 & 16.5 & 0.956 \\
\hline & & & & HRAO & Sep 1996 & Dec 2004 & 5625 & -0.9 & 7.9 & 0.988 \\
\hline Hobart & HOBART26 & Jan 1994 & Nov 2004 & HOB2 & Nov 1995 & Dec 2004 & 2719 & -2.3 & 8.3 & 0.978 \\
\hline Kokee Park & KOKEE & Jan 1994 & Dec 2004 & KOKB & Jan 1994 & Dec 2004 & 18616 & +5.1 & 10.9 & 0.961 \\
\hline Madrid & DSS65 & Apr 1994 & Aug 2004 & MADR & Jan 1994 & Dec 2004 & 765 & -1.3 & 7.4 & 0.980 \\
\hline Matera & MATERA & Jan 1994 & Dec 2003 & MATE & Jan 1994 & Dec 2004 & 7194 & -0.8 & 6.7 & 0.988 \\
\hline McDonald & FD-VLBA & Jan 1994 & Oct 2004 & MD01 & Jan 2004 & Dec 2004 & 2269 & -2.2 & 11.0 & 0.987 \\
\hline Medicina & MEDICINA & Apr 1994 & Dec 2004 & MEDI & Mar 1996 & Dec 2004 & 3411 & -3.0 & 6.0 & 0.993 \\
\hline Mauna Kea & MK-VLBA & Jan 1994 & Oct 2004 & MKEA & Sep 1996 & Dec 2004 & 1150 & -1.0 & 6.5 & 0.891 \\
\hline North Liberty & NL-VLBA & Jan 1994 & Oct 2004 & NLIB & Jan 1994 & Dec 2004 & 2085 & -0.3 & 7.9 & 0.993 \\
\hline Noto & NOTO & Aug 1994 & Oct 2004 & NOTO & Oct 1995 & Sep 2000 & 896 & -2.2 & 8.0 & 0.984 \\
\hline \multirow[t]{2}{*}{ Ny Ålesund } & NYALES20 & Oct 1994 & Dec 2004 & NYAL & Jan 1994 & Dec 2004 & 11626 & -0.9 & 4.6 & 0.994 \\
\hline & & & & NYA1 & Mar 1998 & Dec 2004 & 9333 & -1.4 & 4.2 & 0.995 \\
\hline Onsala & ONSALA60 & Jan 1994 & Dec 2004 & ONSA & Jan 1994 & Dec 2004 & 4712 & -3.5 & 5.3 & 0.994 \\
\hline Pie Town & PIETOWN & Jan 1994 & Oct 2004 & PIE1 & Jan 2004 & Dec 2004 & 2058 & -1.3 & 6.2 & 0.990 \\
\hline Sant Croix & SC-VLBA & Jan 1994 & Oct 2004 & CRO1 & Oct 1995 & Dec 2004 & 1401 & -8.5 & 12.6 & 0.969 \\
\hline Santiago & SANTIA12 & Feb 1994 & Nov 1996 & SANT & Jan 1994 & Dec 2004 & 683 & +4.3 & 9.7 & 0.941 \\
\hline Sheshan & SESHAN25 & Mar 1994 & Dec 2004 & SHAO & Jan 1995 & Dec 2004 & 1200 & -0.3 & 7.5 & 0.996 \\
\hline Tidbinbilla & DSS45 & Jan 1994 & Jun 2004 & TIDB & Jan 1994 & Oct 1997 & 562 & -3.6 & 9.8 & 0.973 \\
\hline Tsukuba & TSUKUB32 & Oct 1998 & Dec 2004 & TSKB & Jan 1994 & Dec 2004 & 3036 & -2.0 & 8.1 & 0.996 \\
\hline Urumqi & URUMQI & Aug 1997 & Nov 2004 & URUM & Nov 1998 & Dec 2004 & 514 & -24.6 & 13.9 & 0.908 \\
\hline Westford & WESTFORD & Jan 1994 & Dec 2004 & WES2 & Jan 1994 & Dec 2004 & 10557 & +4.2 & 6.8 & 0.995 \\
\hline \multirow[t]{2}{*}{ Wettzell } & WETTZELL & Jan 1994 & Dec 2004 & WETT & Jan 1994 & Feb 1997 & 6730 & -1.7 & 8.3 & 0.982 \\
\hline & & & & WTZR & Jan 1996 & Dec 2004 & 18950 & -1.1 & 4.6 & 0.994 \\
\hline
\end{tabular}

(Hugentobler et al 2006). The global GPS solutions include the estimation of satellite orbits, ERPs as well as troposphere parameters and station coordinates for 195 stations altogether (40 to 160 per day). An elevation cut-off angle of $3^{\circ}$ and elevation-dependent weighting (weight $w=\cos ^{2} z$ with zenith angle $z$ ) were applied. For a detailed description of the modeling and processing, see Steigenberger et al (2006). For the comparisons presented here, the results of 1-day solutions were used.

Accordingly, the Deutsches Geodätisches Forschungsinstitut (DGFI), Munich, processed VLBI data of 49 telescopes (4 to 20 per session) from 2613 24-hour sessions between January 4, 1984 and December 30, 2004 using OCCAM 6.1 (Titov et al 2004) and DOGS-CS (Angermann et al 2004). The terrestrial and the celestial reference frame as well as the ERPs were estimated simultaneously to guarantee full consistency within the VLBI solution (Tesmer et al 2004). An elevation cut-off angle of $5^{\circ}$ and a refined stochastic model that mainly consists of an elevation-dependent weighting (Tesmer and Kutterer 2004) were applied. In both software packages, the unknown parameters are estimated with a least-squares adjustment using the Gauß-Markoff model.

The tropospheric path delay $D$ is represented as a function of the zenith angle $z$ and the azimuth $\alpha$ of the observed source (GPS satellite or quasar) by the sum of a hydrostatic zenith delay (modeled) $Z D_{\text {apr }}$ and an estimated zenith delay $Z D_{\text {est }}$ that are both mapped to the zenith angle $z$ with the corresponding mapping functions $f_{\text {apr }}(z)$ and $f_{\text {est }}(z)$. Azimuthal variations of the troposphere are considered by estimating gradients in north-south $(N)$ and eastwest $(E)$ direction:

$D(z, \alpha)=f_{\text {apr }}(z) \cdot Z D_{\text {apr }}+f_{\text {est }}(z) \cdot Z D_{\text {est }}+N \frac{\partial f_{\text {est }}}{\partial z} \cos (\alpha)+E \frac{\partial f_{\text {est }}}{\partial z} \sin (\alpha)$

The a priori zenith delay $Z D_{\text {apr }}$, which is mapped with the hydrostatic Niell (1996) mapping function, is computed for the height of the GPS station using the hydrostatic part of the Saastamoinen (1973) model and the standard atmosphere described by Berg (1948) with a reference pressure of $1013.25 \mathrm{hPa}$ at the ellipsoidal reference height of $0 \mathrm{~m}$.

This value (constant for each station) is also used within the VLBI analysis. Thus, the estimated delay (mapped with the wet Niell (1996) mapping function) is directly comparable for both techniques except for a bias due to 
the effect of the atmosphere between the phase center of the GPS antenna and the reference point of the VLBI telescope. Due to the lack of continuous meteorological observations for all stations, we used the hydrostatic and the wet part of the Saastamoinen (1973) model in order to correct for this theoretical bias. For height differences of more than $20 \mathrm{~m}$, this may not be adequate (depending on the meteorological variability) and the interpretation of results for these stations (in our case the GPS sites HARK and HART at Hartebeesthoek, McDonald and Urumqi) has to be done with caution. $Z D_{\text {est }}$ will be called zenith wet delay (ZWD) in the following, although it also contains a hydrostatic part due to deviations of the actual atmospheric conditions from the standard atmosphere used for the computation of $Z D_{\text {apr }}$.

For the mapping of the troposphere gradients, Bernese uses the partial derivative of the wet Niell (1996) mapping function as described in Eq. (1), whereas OCCAM applies the model of MacMillan (1995). The differences in the estimated troposphere gradients when applying these two different models are in general on the level of a few hundredths of a millimeter and therefore negligible.

For GPS, the temporal resolution of the troposphere zenith delay parameters is chosen to be $2 \mathrm{~h}$ due to the huge computation load of the processing, whereas the VLBI solution has a 1-hour resolution. Thus, the GPS values are interpolated linearly to compare the results of both techniques. The GPS-derived gradients in north-south and eastwest direction are estimated once per day and per site using a linear function with a 24-hour parameter spacing. As in the VLBI solution one pair of gradients per station is solved for as constant offsets, the GPS gradients are interpolated linearly to the middle of the VLBI session. Due to the poor observing geometry of some VLBI sessions, especially the older ones, the VLBI-derived gradients were not estimated completely freely as GPS-derived values, but had to be constrained with $2.0 \mathrm{~mm}$ with respect to the a priori values being zero.

\section{Troposphere zenith delays}

\subsection{Comparison with IGS troposphere parameters}

Since 1997, the IGS has provided a combined troposphere product (Gendt 1996), namely the zenith total delay (ZTD, sum of the hydrostatic and the wet zenith delay) computed as a weighted mean of the different AC solutions. At the moment, seven ACs are contributing to the IGS final troposphere product using six different software packages (the near real-time ZTD product will not be considered here). The ZTD contributions are combined independently from the station positions used, not considering inconsistencies introduced by changes in the reference frame used for datum definition or model changes (e.g. cut-off angle and mapping function).

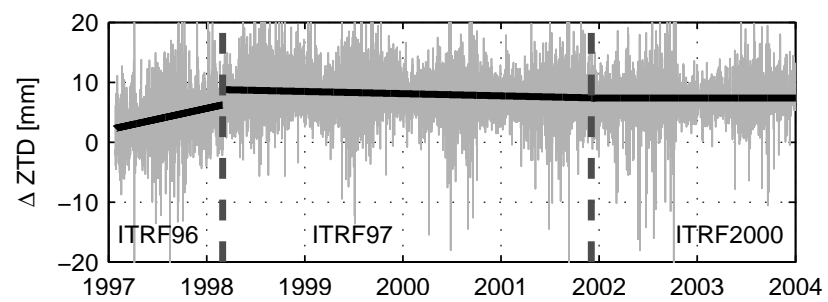

Fig. 1 Differences between IGS and reprocessed zenith total delay (2-hourly) for Algonquin Park (ALGO). The different drift behavior of the three time periods coincides very well with the different reference frame realizations (marked by dashed vertical lines): ITRF96: $3.6 \mathrm{~mm} / \mathrm{y}$, ITRF97: -0.4 mm/y, ITRF2000: $0.0 \mathrm{~mm} / \mathrm{y}$

Figure 1 reveals these inconsistencies by comparing the IGS ZTD with our reprocessed GPS solution for the station Algonquin Park (Canada). We can see a systematic bias of about $7 \mathrm{~mm}$ between both solutions, which is probably due to different models for the phase centers of receiver and satellite antennas. The IGS uses relative phase center corrections (relative variations with respect to the reference antenna AOAD/M_T) for receiver antennas only, whereas our GPS solution is based on absolute values for receiver (Menge et al 1998) and satellite antennas (Schmid and Rothacher 2003). More details on the effect of different phase center models on global solutions can be found in Schmid et al (2005) and Schmid et al (2006).

The varying drift behavior of the ZTD difference obviously coincides with the different reference frames used for datum definition by the IGS: ITRF96 (Boucher et al 1998), ITRF97 (Boucher et al 1999) and ITRF2000 (Altamimi et al 2002). As long as ITRF2000 is used, both within the IGS and for the reprocessing, the drift of the 
difference between both solutions is zero as expected. In the time interval when ITRF97 was used for the IGS solution, the drift is $-0.4 \mathrm{~mm} / \mathrm{y}$, with ITRF96 it is even $+3.6 \mathrm{~mm} / \mathrm{y}$. The interpretability of such inhomogeneous time-series for long-term climatological studies is questionable.

\subsection{GPS/GPS co-locations}

GPS/GPS co-locations (more than one GPS site operated at one station at the same time) can be used to assess the internal consistency of the GPS solution. Figure 2 shows the ZTD differences between the two sites NYAL and NYA1 operated at Ny Ålesund (Norway) for the IGS solution and the reprocessed solution. The IGS difference clearly contains an annual signal with an amplitude of $2.5 \pm 0.1 \mathrm{~mm}$ before 2003 . The amplitude of the signal decreases in 2003 and the signal vanishes in 2004. This signal is probably induced by the contribution of different ACs to the combined solutions of the two sites: NYAL data is analyzed by the European Space Operations Center (ESOC, until January 2004), the Jet Propulsion Laboratory (JPL, until March 2004), the National Oceanic and Atmospheric Administration (NOAA, until December 2004), Natural Resources Canada (NRCan), and the Scripps Institution of Oceanography (SIO); NYA1 data by CODE, GeoForschungsZentrum Potsdam (GFZ), JPL and SIO for the time period considered in Fig. 2.
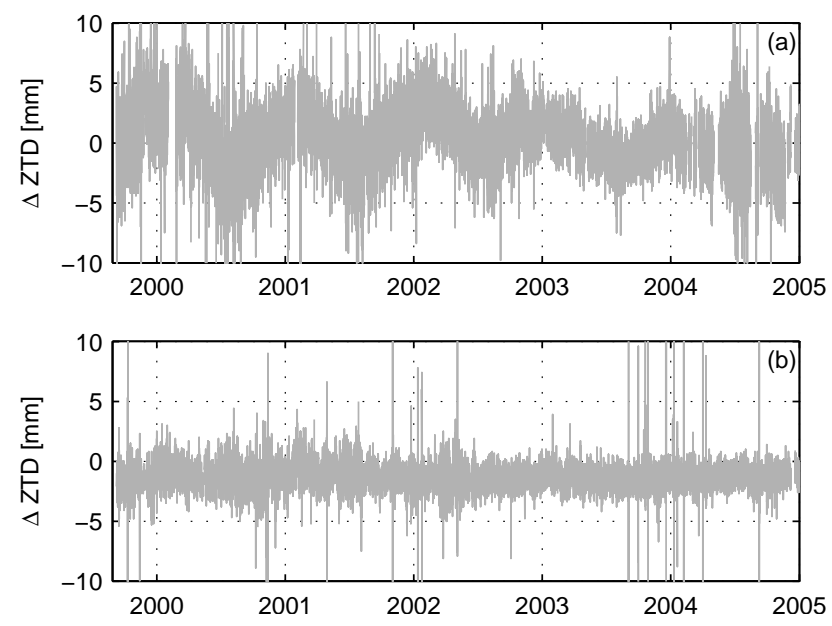

Fig. 2 2-hourly ZTD differences for the GPS/GPS co-location Ny Ålesund (NYAL and NYA1): (a) IGS time-series: RMS 4.3 mm, correlation 0.994, (b) reprocessed time-series: RMS $1.7 \mathrm{~mm}$, correlation 0.999. Noisy data before September 1999 (replacement of the old ROGUE SNR-8 receiver at station NYAL) have been excluded from both comparisons, (a) and (b).

The periodic signal vanishes as soon as the configuration of the ACs contributing to the combined solution of NYAL changes (beginning of 2004). According to Dong et al (2002) systematic errors in the different software packages and processing strategies are a major reason for such seasonal signals visible in the differences. The IGS solution for the two sites at Troms $\varnothing$ (Norway) contains a similar periodic signal whereas the other GPS/GPS co-locations listed in Table 2 do not show such a behavior.

Bias, drift, RMS and correlation coefficients between the ZTD of co-located GPS sites for the IGS and the reprocessed solution are displayed in Table 2 . While the differences in correlation are rather small, the improvement of the reprocessed solution with respect to the IGS solution is quite evident as regards drift and RMS. The drift of the ZTD difference (physically/theoretically expected to be close to zero) is smaller by a factor of at least two for most sites of the reprocessed solution. Only for Troms $\varnothing$ the drift is almost the same, whereas the RMS for the reprocessed solution is smaller by a factor of 2.5 .

The results for Yakutsk, Russia (YAKZ/YAKT: very high drift for IGS, RMS is worse for reprocessed solution) and the reprocessed solution for Hartebeesthoek (HRAO/HART) have to be handled with care as the number of ZTD parameters contributing to the comparison of these sites is small. The ZTD biases of the GPS/GPS co-locations (corrected for the height difference) range from -2.5 to $4.3 \mathrm{~mm}$ for the IGS solution and from -0.9 to $2.5 \mathrm{~mm}$ for the reprocessed solution. The latter biases provide an estimate of the systematic errors of GPS. They can be regarded as lower bounds for the expected biases between zenith delay estimates from co-located GPS and VLBI antennas, as systematic VLBI errors additionally come into play. 
Table 2 Comparison of 2-hourly estimated zenith total delays for GPS/GPS co-locations: IGS combined troposphere product and reprocessed GPS solution. The bias has been corrected for the theoretical bias due to the height difference between the two GPS antennas. Bias, drift and RMS correspond to the difference time-series of the two stations, the correlation to the raw time-series.

\begin{tabular}{llrrrrrrrrrr}
\hline Station 1 & \multirow{2}{*}{ Station 2 } & \multicolumn{2}{c}{ \# Parameters } & \multicolumn{2}{c}{ Bias [mm] } & \multicolumn{2}{c}{ Drift [mm/y] } & \multicolumn{2}{c}{ RMS [mm] } & \multicolumn{2}{c}{ Correlation } \\
& & IGS & Repr. & IGS & Repr. & IGS & Repr. & IGS & Repr. & IGS & Repr. \\
\hline HRAD & HARK & 4118 & 9912 & 4.3 & 2.5 & 0.9 & 0.5 & 6.5 & 5.4 & 0.993 & 0.996 \\
HRAD & HART & 5150 & 618 & 3.7 & 1.9 & 2.0 & 0.8 & 5.7 & 5.1 & 0.994 & 0.993 \\
NYAL & NYA1 & 25777 & 27390 & 0.8 & 0.3 & -0.7 & -0.2 & 5.1 & 4.4 & 0.992 & 0.991 \\
TROM & TR01 & 22886 & 24582 & 1.8 & 1.5 & 0.3 & 0.3 & 6.3 & 2.5 & 0.993 & 0.998 \\
YARR & YAR2 & 3503 & 7228 & -2.5 & -0.9 & -1.2 & -0.3 & 4.7 & 2.8 & 0.990 & 0.997 \\
YAKZ & YAKT & 816 & 1257 & 0.2 & -0.4 & 6.8 & 0.2 & 3.0 & 3.6 & 0.997 & 0.996 \\
\hline
\end{tabular}

\subsection{GPS/VLBI co-locations}

Outliers have been removed from our reprocessed series using different criteria: GPS parameters with a formal error exceeding the three-fold mean formal error $(3 \sigma)$ of the whole time-series were excluded. In case of VLBI, only parameters determined by at least three observations were used (as the time intervals of the 1-hourly zenith delays estimated from VLBI do not always coincide with integer hours as in the case of GPS, the values and the numbers of observations were interpolated to integer hours). The number of troposphere parameters excluded due to these criteria are on average $5.3 \%$ for VLBI and $0.9 \%$ for GPS.

The VLBI and GPS ZWD estimates, as well as their difference, are plotted in Fig. 3 for Algonquin Park. This station has been selected as it has the most complete GPS time-series and as its VLBI telescope participated in a comparatively large number of VLBI sessions (although the VLBI observations are sparser before mid 1997). The bias of the ZWD difference is $7.8 \mathrm{~mm}$, its standard deviation is $5.8 \mathrm{~mm}$. After correcting for the theoretical bias due to the height difference between the reference points as described in Section 2, a very small bias of only $-0.5 \mathrm{~mm}$ remains. The ZWD difference also shows a seasonal pattern: in summertime, when the water content of the atmosphere as well as the variability of the atmosphere is larger, the ZWD difference also shows more scatter.

The RMS of the ZWD differences, their bias corrected for the height difference and the correlation coefficients between both time-series are listed in Table 1. Occasionally observing VLBI stations with less than 500 estimated troposphere parameters during the time interval considered for the comparisons have been excluded. In general, the biases between both techniques are at the level of a few millimeters. They reveal a quite good agreement of both techniques and confirm the level of agreement that could be expected from analyzing the GPS/GPS co-locations (see Sect. 3.2).
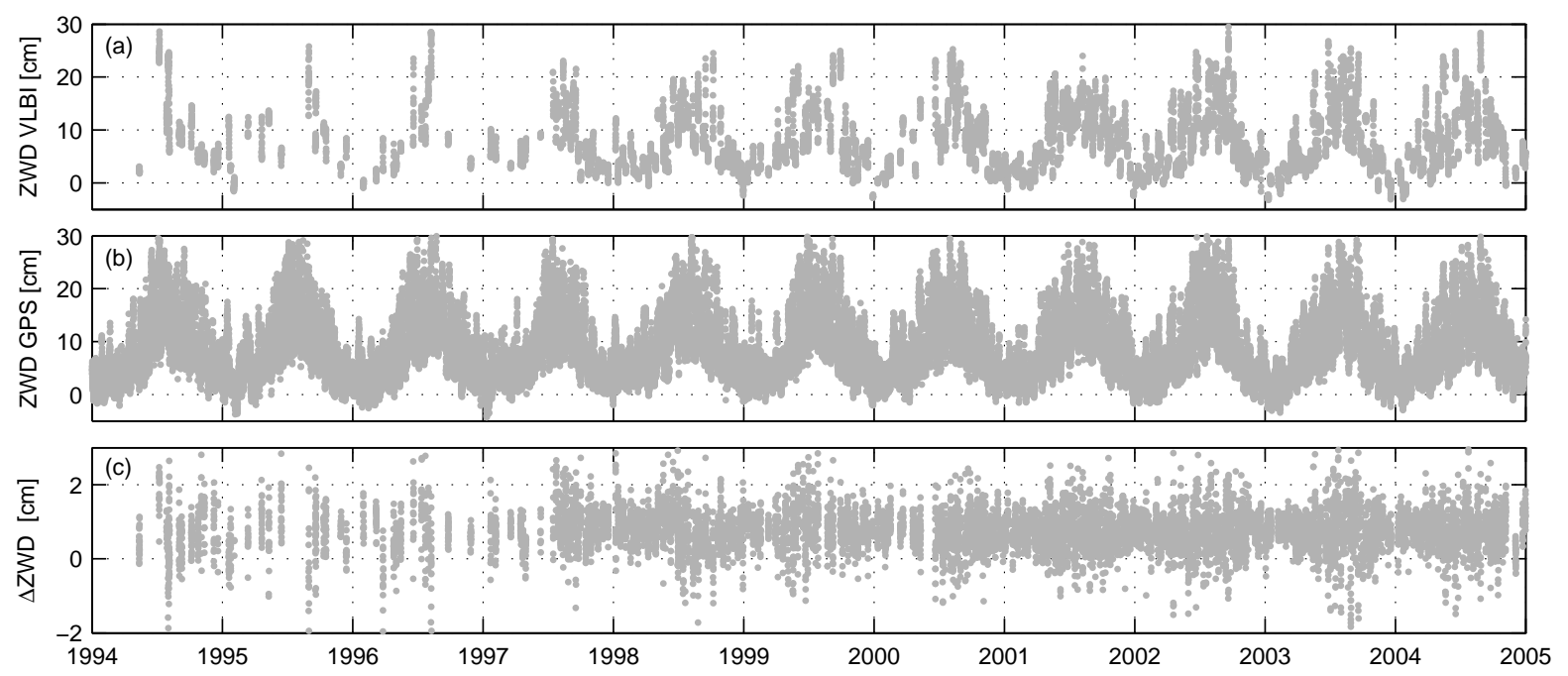

Fig. 3 Time-series of estimated zenith wet delays for Algonquin Park: (a) VLBI (1-hourly), (b) GPS (2-hourly), (c) difference between GPS and VLBI (1-hourly interpolated). 
Table 3 Long-term trends estimated from 2-hourly GPS- and 1-hourly VLBI-derived ZWD values: For the adjustment type oda offset, drift and annual signal were estimated; for odasa a semi-annual signal was estimated in addition. The index all denotes that all epochs of the GPS and VLBI time-series were used for the adjustment, the index id means that only identical epochs were used.

\begin{tabular}{|c|c|c|c|c|c|c|c|c|c|}
\hline \multirow[b]{2}{*}{ Adj. } & \multirow{2}{*}{$\begin{array}{l}\text { Station } \\
\text { Solution }\end{array}$} & \multicolumn{2}{|c|}{ ALGO } & \multicolumn{2}{|c|}{ NYA1 } & \multicolumn{2}{|c|}{ NYAL } & \multicolumn{2}{|c|}{ WTZR } \\
\hline & & $\begin{array}{c}\text { \# ZWD } \\
\text { Par. }\end{array}$ & $\begin{array}{c}\text { Drift } \\
{[\mathrm{mm} / \mathrm{y}]}\end{array}$ & $\begin{array}{l}\text { \# ZWD } \\
\text { Par. }\end{array}$ & $\begin{array}{c}\text { Drift } \\
{[\mathrm{mm} / \mathrm{y}]}\end{array}$ & $\begin{array}{l}\text { \# ZWD } \\
\text { Par. }\end{array}$ & $\begin{array}{c}\text { Drift } \\
{[\mathrm{mm} / \mathrm{y}]}\end{array}$ & $\begin{array}{l}\text { \# ZWD } \\
\text { Par. }\end{array}$ & $\begin{array}{c}\text { Drift } \\
{[\mathrm{mm} / \mathrm{y}]}\end{array}$ \\
\hline \multirow{3}{*}{ oda } & $\mathrm{GPS}_{\text {all }}$ & 47775 & \multirow{3}{*}{$\begin{array}{r}0.30 \pm 0.06 \\
-0.34 \pm 0.16 \\
-0.34 \pm 0.23 \\
-0.33 \pm 0.23\end{array}$} & 27933 & \multirow{3}{*}{$\begin{array}{r}0.15 \pm 0.08 \\
0.85 \pm 0.09 \\
-0.91 \pm 0.23 \\
-0.81 \pm 0.23\end{array}$} & 42149 & \multirow{3}{*}{$\begin{array}{l}0.73 \pm 0.04 \\
0.85 \pm 0.09 \\
0.65 \pm 0.14 \\
0.86 \pm 0.14\end{array}$} & 38607 & \multirow{3}{*}{$\begin{array}{l}0.39 \pm 0.06 \\
0.09 \pm 0.06 \\
0.83 \pm 0.12 \\
0.79 \pm 0.12\end{array}$} \\
\hline & $\operatorname{VLBI}_{a l l}$ & 10076 & & 12903 & & 12903 & & 23715 & \\
\hline & $\begin{array}{l}\mathrm{GPS}_{i d} \\
\mathrm{VLBI}_{i d}\end{array}$ & 4875 & & 4600 & & 5694 & & 9324 & \\
\hline \multirow{3}{*}{ odasa } & GPS $_{\text {all }}$ & 47775 & \multirow{3}{*}{$\begin{array}{r}0.36 \pm 0.06 \\
-0.15 \pm 0.15 \\
-0.19 \pm 0.23 \\
-0.19 \pm 0.22\end{array}$} & 27933 & \multirow{3}{*}{$\begin{aligned} 0.15 & \pm 0.08 \\
0.84 & \pm 0.09 \\
-0.87 & \pm 0.23 \\
-0.77 & \pm 0.23\end{aligned}$} & 42149 & \multirow{3}{*}{$\begin{array}{l}0.77 \pm 0.04 \\
0.84 \pm 0.09 \\
0.65 \pm 0.14 \\
0.85 \pm 0.14\end{array}$} & 38607 & \multirow{3}{*}{$\begin{array}{l}0.45 \pm 0.06 \\
0.20 \pm 0.06 \\
0.90 \pm 0.12 \\
0.86 \pm 0.12\end{array}$} \\
\hline & $\mathrm{VLBI}_{\text {all }}$ & 10076 & & 12903 & & 12903 & & 23715 & \\
\hline & $\operatorname{GPS}_{i d}$ & 4875 & & 4600 & & 5694 & & 9324 & \\
\hline
\end{tabular}

For Urumqi (China) the bias (after correction for the height difference between the reference points) is very high $(-24.6 \mathrm{~mm})$. As the GPS antenna differs by about $1174 \mathrm{~m}$ in altitude from the VLBI telescope, the major part of this bias is certainly caused by deficiencies of the standard atmosphere that is applied to compute the input arguments of the Saastamoinen (1973) model used to correct the estimated zenith delay for the height difference. Also, the GPS sites at Hartebeesthoek (South Africa), which are not that close to the VLBI telescope (HARK and HART, height difference of about $130 \mathrm{~m})$, show a much larger bias $(-9.2 \mathrm{~mm}$ for both sites) than the site HRAO (-0.9 mm bias). On the other hand, the $-2.2 \mathrm{~mm}$ bias at McDonald (USA) is quite small although the height difference is about $400 \mathrm{~m}$.

Most stations with RMS values exceeding $10 \mathrm{~mm}$ are located close to the equator (Sant Croix, U.S. Virgin Islands; Fortaleza, Brazil; Kokee Park, Hawaii). Probably, the higher variability of the troposphere in the tropics is responsible for this effect. As a measure for the stability of these results, the biases derived from the CONT02 campaign (eight VLBI telescopes observing continuously for two weeks during October 2002, Thomas and MacMillan 2003) were compared to those obtained from the long time-series: the biases for the eight stations in general agree on the level of below $1 \mathrm{~mm}$ (see Thaller et al 2006).

Only a few stations have suitable data (frequent observations covering a time span of several years) to determine a reliable long-term trend in the estimated ZWD. The number of stations further decreases when excluding stations with discontinuities due to equipment changes or tracking problems (see Sect. 3.4). Offset, drift, amplitude and phase of an annual signal were estimated simultaneously in a least-squares adjustment for the stations Algonquin Park, Ny Ålesund and Wettzell (see Table 3). The drifts derived from all observations of the GPS and VLBI timeseries often differ significantly from each other, as well as the two GPS-derived values for Ny Ålesund. Haas et al (2003) pointed out that the different sampling is a critical issue for the determination of trends in long time-series of troposphere delays.

Limiting the time-series to epochs with common estimates for both techniques increased the similarity of all trends to the $95 \%$ confidence level except for NYAL. Also, the size of the drift significantly changes when using the identical sampling. For ALGO, the estimated rates for identical observations are almost the same as the VLBI all rate for all observations, but for NYA1 and WTZR, the values for identical observations are completely different compared to that using all observations. This clear dependence on the sampling indicates that the series contain signals that are neither of linear nor of annual nature.

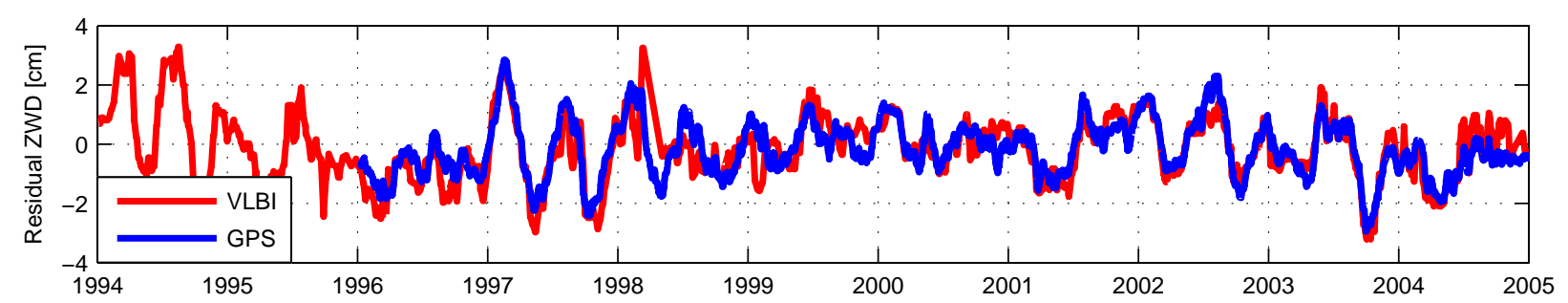

Fig. 4 GPS and VLBI ZWD residual time-series (smoothed with a 30-day median filter) for Wettzell after removing offset, trend and annual signal. 
Figure 4 illustrates the GPS and VLBI ZWD residuals (smoothed with a 30-day median filter) for Wettzell (GPS site WTZR only) after removing offset, trend and the annual signal. An irregular semi-annual signal with changing amplitude can be detected. The residuals of the other stations have comparable properties. If a semiannual signal is estimated in addition, the periodical fraction from the residual signal is removed. However, this does not significantly decrease the dependence on the sampling (see lower part of Table 3). Therefore, the trends of the troposphere ZWDs have to be interpreted with care, especially when thinking of climatological or global change phenomena.

\subsection{GPS tracking problems}

The comparison of ZWD parameters derived from the two independent techniques, GPS and VLBI, allows us to detect anomalies in one of the two time-series. Figure 5 illustrates the effect of a tracking anomaly of the GPS antenna at Kokee Park (Hawaii): For a time period of several months, the ZWD difference between VLBI and GPS is shifted by a mean value of $3.2 \mathrm{~cm}$. This systematic offset is generated by a reduced tracking performance of the GPS antenna, which results in a dramatically reduced observation rate. Especially satellites at elevations below $35^{\circ}$ are tracked very sparsely.
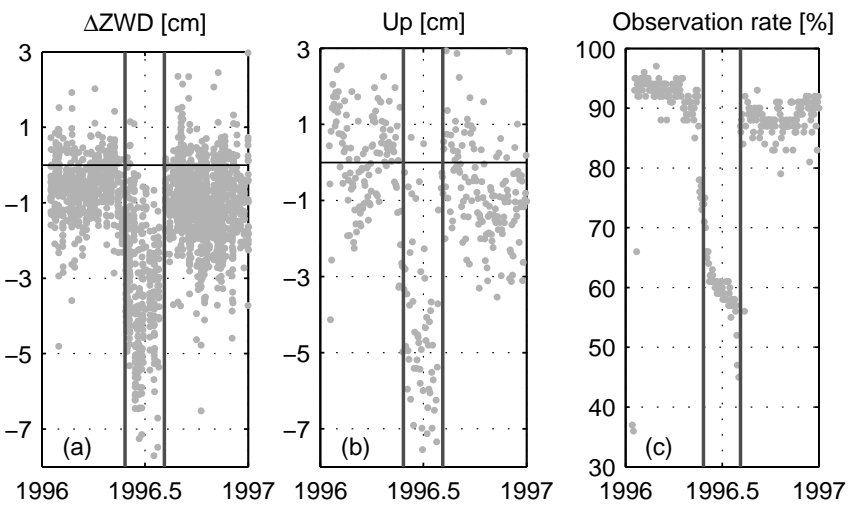

Fig. 5 Tracking anomaly of the GPS antenna at Kokee Park (start and end are indicated by vertical lines): (a) ZWD difference between VLBI and GPS, (b) GPS station height with respect to the long-term mean, (c) observation rate of the GPS receiver.

Due to the lack of observations at low elevations, the correlation between the troposphere zenith delay and the station height is unusually high, resulting in a systematic bias in the ZWD difference as well as in the height of the GPS station (4.2 cm with respect to the long-term mean). According to Rothacher (2002), errors in the station height $\delta h$ are related to a tropospheric bias $\delta \rho_{\text {trp }}$ by the rule of thumb

$\delta h \approx \frac{\delta \rho_{\mathrm{trp}}}{\cos z_{\max }}$

with the maximum zenith angle (cut-off angle) $z_{\max }$. Introducing the zenith delay bias of $3.2 \mathrm{~cm}$ and the height bias of $4.2 \mathrm{~cm}$ in Eq. (2), one obtains an effective cut-off angle due to degraded tracking of about $50^{\circ}$, which only roughly agrees with the $35^{\circ}$ derived from the observation statistics. An explanation for that might be the elevationdependent weighting of the observations.

After an antenna replacement in August 1996, the observation rate and also the ZWD and the height values return to normal. When excluding data affected by the tracking problem from the computation of the GPS/VLBI troposphere bias and RMS (as shown in Table 1), the bias is reduced from 5.1 to $4.7 \mathrm{~mm}$ and the RMS from 10.9 to $10.2 \mathrm{~mm}$.

Another example of GPS tracking problems is the site WETT in Wettzell: In the last few months of its operation time (before it was switched off in February 1997) this receiver showed a curious behavior (all coordinate components are biased up to $5 \mathrm{~cm}$ ) resulting in a much higher RMS $(8.3 \mathrm{~mm})$ compared to the receiver WTZR $(4.6 \mathrm{~mm})$ and in a lower correlation with the respective VLBI-derived values (see Table 1). When excluding this problematic time period, the RMS is reduced to $6.3 \mathrm{~mm}$. 
Table 4 Comparison of troposphere gradients for GPS/GPS co-locations of the reprocessed GPS solution.

\begin{tabular}{|c|c|c|c|c|c|c|c|c|c|}
\hline \multirow[t]{2}{*}{ Station } & \multirow{2}{*}{ Site 1} & \multirow[t]{2}{*}{ Site 2} & \multirow{2}{*}{ \# Parameters } & \multicolumn{3}{|c|}{ North-South Gradients } & \multicolumn{3}{|c|}{ East-West Gradients } \\
\hline & & & & $\begin{array}{l}\text { Offset } \\
{[\mathrm{mm}]}\end{array}$ & $\begin{array}{c}\text { RMS } \\
{[\mathrm{mm}]}\end{array}$ & Corr. & $\begin{array}{r}\text { Offset } \\
{[\mathrm{mm}]}\end{array}$ & $\begin{array}{l}\text { RMS } \\
{[\mathrm{mm}]}\end{array}$ & Corr. \\
\hline Hartebeesthoek & HRAO & HARK & 851 & 0.02 & 0.35 & 0.759 & -0.16 & 0.38 & 0.719 \\
\hline Hartebeesthoek & HRAO & HART & 54 & 0.11 & 0.28 & 0.757 & 0.06 & 0.42 & 0.750 \\
\hline Miami Beach & MIA1 & AOML & 190 & 0.50 & 0.56 & 0.655 & 0.38 & 0.62 & 0.546 \\
\hline Ny Ålesund & NYAL & NYA1 & 2309 & 0.10 & 0.14 & 0.775 & 0.04 & 0.13 & 0.767 \\
\hline Thule & THU1 & THU3 & 78 & 0.20 & 0.70 & 0.414 & -0.40 & 0.53 & 0.450 \\
\hline Troms $\varnothing$ & TROM & TR01 & 2051 & 0.08 & 0.15 & 0.814 & 0.07 & 0.10 & 0.876 \\
\hline Yarragadee & YARR & YAR2 & 615 & -0.03 & 0.17 & 0.901 & 0.07 & 0.17 & 0.879 \\
\hline Yakutsk & YAKZ & YAKT & 104 & 0.07 & 0.09 & 0.950 & -0.07 & 0.11 & 0.944 \\
\hline Wettzell & WETT & WTZR & 379 & 0.24 & 0.68 & 0.296 & 0.32 & 0.83 & 0.218 \\
\hline
\end{tabular}

\section{Troposphere gradients}

\subsection{GPS/GPS co-locations}

Offset, RMS and correlation coefficients between troposphere gradients of GPS/GPS co-locations at one station, derived from the reprocessed solution, are listed in Table 4. In addition to the sites in Table 2, the sites in Miami (AOML and MIA1) and two co-locations where IGS troposphere parameters are not available for both sites (Thule and Wettzell) are included. In general, the correlation of the troposphere gradients is worse than that of the zenith delays: this can be explained by a much smaller and less clear annual signal in the troposphere gradients. However, if a co-located pair of sites shows especially large RMS differences and low correlations, this generally indicates a problem at one of the stations, like the tracking problems with WETT at Wettzell already mentioned in Section 3.4.

The correlation between the two GPS sites WETT and WTZR for both, the east-west and the north-south gradients, is below 0.3 and the RMS values of the differences with respect to each other are the largest ones listed in Table 4. The site THU1 at Thule (Greenland) also shows a degraded performance resulting in high RMS values and small correlations for the respective gradients (accompanied by a small number of common parameters for the two antennas). The reasons for the bad agreement of the sites at Miami Beach are unknown.

\subsection{GPS/VLBI co-locations}

Figure 6 shows the mean troposphere gradients in north-south and east-west direction computed from all VLBI and GPS gradient parameters for all co-located sites. The constraints on the a priori values (that are zero) used for the gradients estimated by VLBI (see Sect. 2) might be the reason for the generally smaller VLBI gradient estimates. However, it is difficult to assess the influence of the constraints on the estimated gradient parameters in general. For sessions, where the gradients are well-determined by the observations themselves, the constraints have no significant influence. For weak sessions (occasionally occurring before 1990), there is of course some bias, in extreme cases the gradient estimates could even be dominated by the constraint.

Despite this deficiency the agreement of the two techniques is pretty good: both show a significant latitudedependence of the north-south gradient. This systematic effect is caused by the temperature difference between the poles and the equator whose sign does not show a seasonal dependence (Chen and Herring 1997).

The east-west gradients are generally smaller for both techniques, a fact already known from the studies of Meindl et al (2004). One exception is the station SANT (Santiago de Chile) with a considerable east-west troposphere gradient detected by both techniques. Santiago is located in the Central Valley of Chile, about $80 \mathrm{~km}$ inland of the coast and very close to the Andes. Maritime air can stream into the Central Valley through valleys like those of the Mapocho and Maule river beds (Miller 1976). This wet air from the west and the dry air above the Andes in the east might be a reasonable explanation for the large troposphere gradient.

At the Fortaleza (FORT) and Westford (WES2) sites, also located near the coast, the gradients from GPS and VLBI significantly differ in both the north and east component: in the case of Fortaleza the VLBI north gradient is small and the east gradient is large, whereas GPS shows the opposite. For Westford, the behavior of the gradients is vice versa. This effect might be related to the characteristics of the coastlines: the coastline near Fortaleza ranges from north-west to south-east, whereas that close to Westford ranges from north-east to south-west. One would expect the maximum gradients to appear in north-east to south-west and in north-west to south-east direction, 


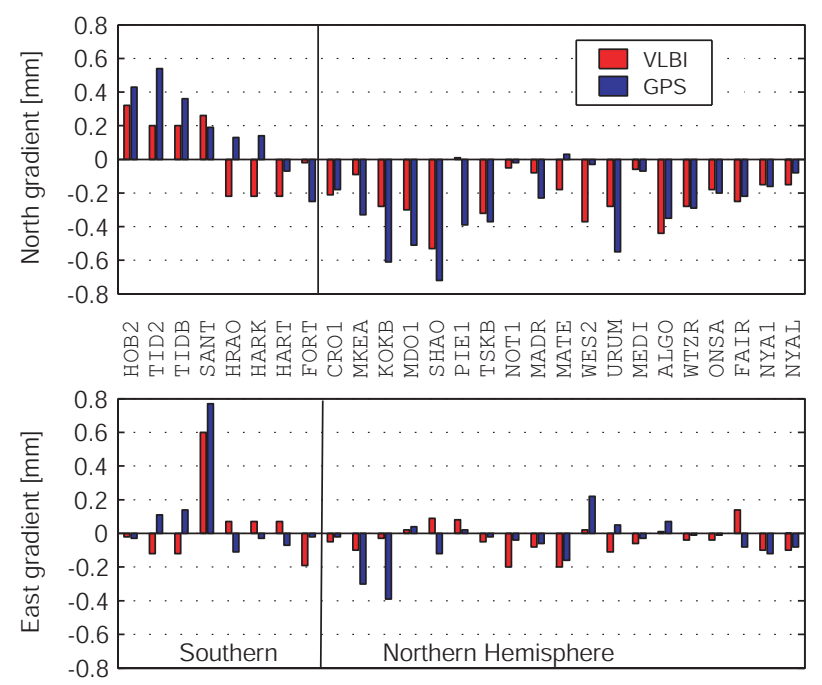

Fig. 6 Mean north-south and east-west troposphere gradients determined by VLBI and GPS. The stations are sorted by latitude (from south to north).

respectively. Obviously, these gradients are mapped into the north-south direction for the one technique and into the east-west direction for the other one, which could be due to station-specific phenomena like multipath, obstructions, distribution of the observed quasars, etc. that have different effects on the two techniques.

To get an idea of the level of similarity between the signals in the time-series of VLBI- and GPS-derived tropospheric gradients, we also compared such time-series. As Fig. 7 reveals, gradients from GPS and VLBI generally show the same episodic behavior, if the time-series are dense and precise enough for both techniques. The amplitude and phase of the annual signals in the north-south gradient are shown in Fig. 8. Although the amplitudes of these signals are usually small (some tenths of a millimeter) the GPS- and VLBI-derived signals show a good agreement for those stations, where the VLBI amplitude significantly differs from zero (e.g. SHAO, TSKB, MKEA). Due to the fact that the annual fraction in the gradients often is quite small compared to the overall episodic behavior and due to the comparatively irregular and sparse distribution of the VLBI observations, the amplitude and especially the phase can only be significantly determined for some VLBI stations. Urumqi, for example, has almost the same amplitude for both techniques, but the phase is shifted by about $140^{\circ}$ (formal error of the VLBI phase estimate: $\left.80^{\circ}\right)$.

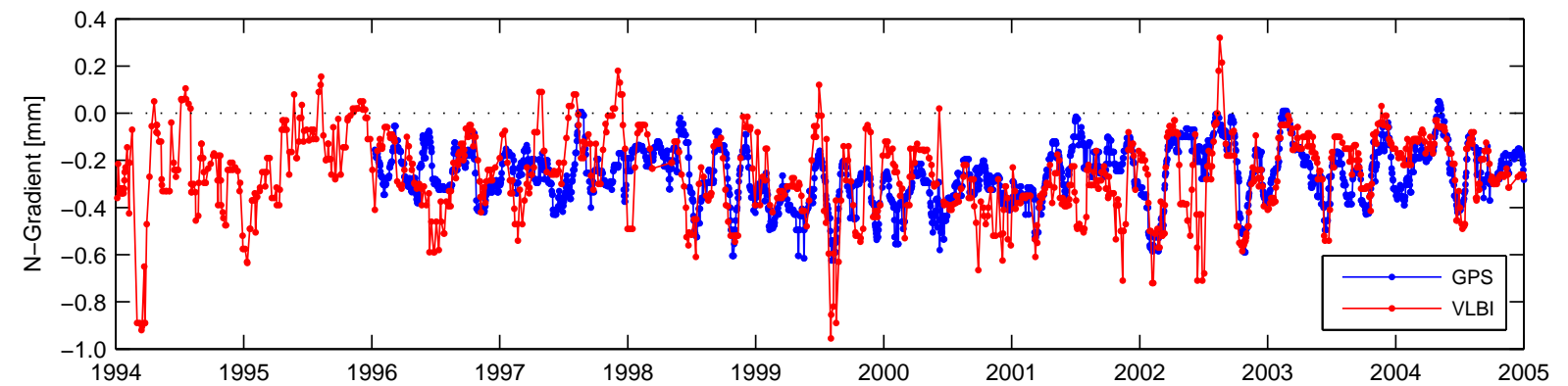

Fig. 7 GPS and VLBI north-south troposphere gradient time-series (smoothed with a 30-day median filter) for Wettzell (WTZR). The correlation coefficient of these time-series is 0.615 whereas it is only 0.284 for the site WETT, an effect also visible in other comparisons, see Sections 3.4 and 4.1. 


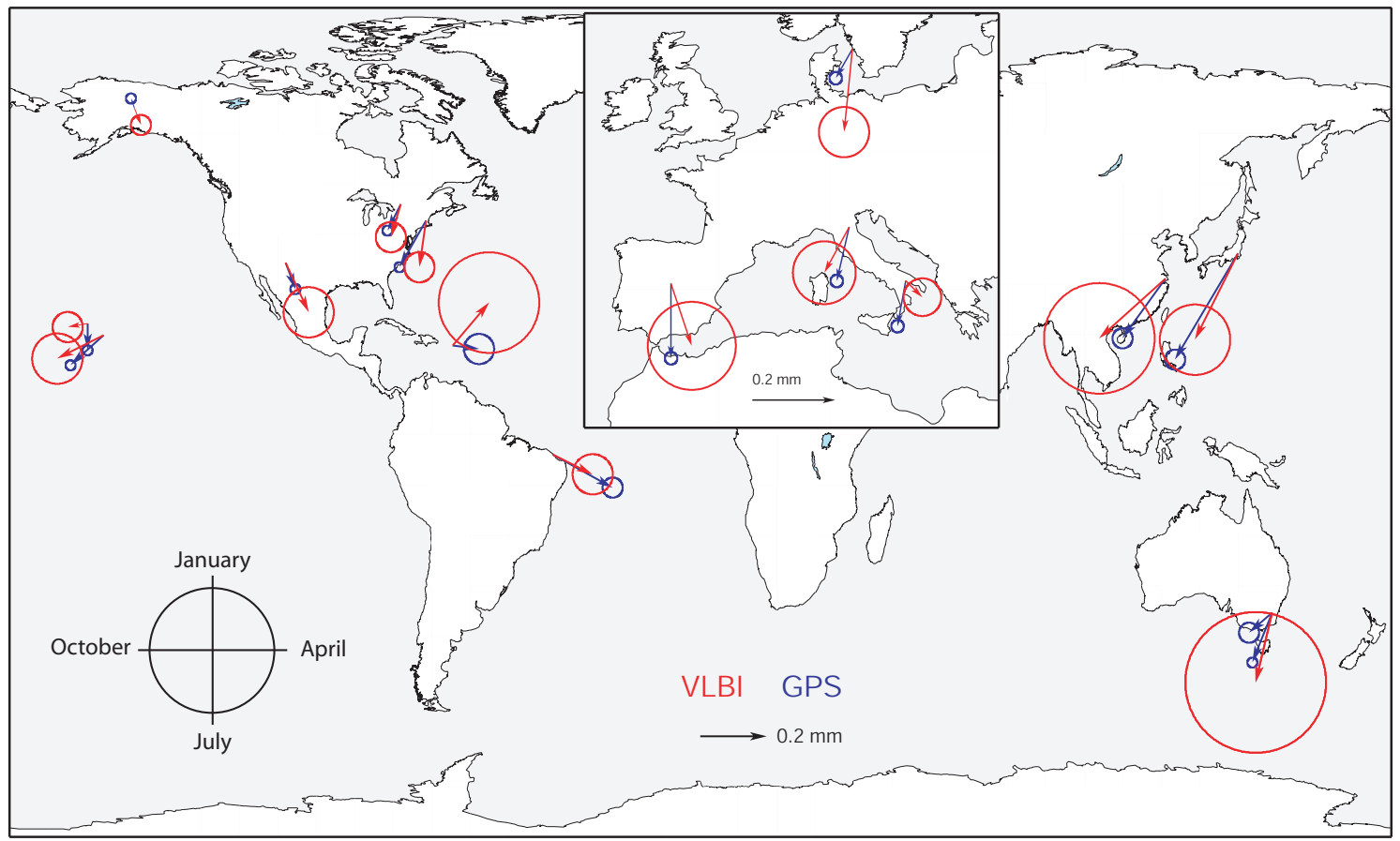

Fig. 8 Amplitude and phase of the annual signals in the north-south troposphere gradients. The length of the arrows represents the amplitude, the direction of the arrows the date of the annual maximum. The formal errors of the estimated amplitudes are represented by circles. Only stations where the VLBI amplitude could be significantly determined are shown.

\section{Conclusions}

The homogeneity of the reprocessed GPS and VLBI time-series and the harmonized modeling and parameterization are the major reason for the very good agreement in the estimated troposphere parameters of the two techniques. The remaining biases between the GPS and VLBI estimates (for ZWD generally smaller than $4 \mathrm{~mm}$ with a mean value of $-0.8 \mathrm{~mm}$, in case of horizontal gradients generally smaller than $0.2 \mathrm{~mm}$ ), are expected to be due to remaining systematic effects within the individual techniques and should be further investigated in the future.

In case of GPS, one has to consider antenna phase center variations, the effect of radomes and any kind of equipment change. All these examples are expected to be closely connected to the GPS scale drift with respect to ITRF. Schmid et al (2006) show that the mean ZWD biases between GPS and VLBI can be reduced by a factor of about six (from +5.3 to $-0.8 \mathrm{~mm}$ ) using absolute phase center variations for receiver and satellite antennas (as done for the studies presented here) instead of relative ones for receiver antennas only. For VLBI, the modeling of gravitational sag and thermal deformations of the telescopes should be considered, which was not the case in these studies. Besides, it is expected, that the small number of GPS stations in the early years as well as the small number and the inhomogeneous distribution of VLBI telescopes cause additional systematic effects.

The results of this paper suggest that in the near future the observations of the two space-geodetic techniques, VLBI and GPS, should be rigorously combined not only in terms of station coordinates and Earth orientation parameters, what already turned out to be profitable for both sides, but also in terms of troposphere zenith delays and gradients. Thaller et al (2006) show that the daily repeatabilities of both techniques are improved by thoroughly combining station positions and Earth orientation parameters.

A comparable improvement is expected to be achieved in the ITRF2005 combination efforts, presumably of smaller significance, because the data contributing to ITRF2005 was not homogenized in detail (concerning a priori models, parameterization etc.) and the GPS data was not reprocessed. If the remaining small systematic differences between VLBI- and GPS-derived troposphere zenith delays and gradients could be understood or handled adequately, such independent information would contribute much stability and, as a consequence, reliability to combined equation systems. Such a rigorous combination (also including GPS reprocessing) is planned by the IERS for the near future (Rothacher and Ma 2006). 
Acknowledgements The authors would like to thank the International GNSS Service (Beutler et al 1999) and the International VLBI Service for Geodesy and Astrometry (Schlüter et al 2002) for providing GPS and VLBI observation data. The GPS reprocessing project was funded by the Deutsche Forschungsgemeinschaft (German Research Foundation), project number 233069. The valuable comments of the reviewers J. Davis, D. MacMillan, an anonymous reviewer and the editor-in-chief W. Featherstone are gratefully acknowledged.

\section{References}

Altamimi Z, Sillard P, Boucher C (2002) ITRF2000: A new release of the International Terrestrial Reference Frame for earth science applications. J Geophys Res 107(B10):2214, DOI 10.1029/2001JB000561

Angermann D, Drewes H, Krügel M, Meisel B, Gerstl M, Kelm R, Müller H, Seemüller W, Tesmer V (2004) ITRS combination center at DGFI - a terrestrial reference frame realization 2003. Deutsche Geodätische Kommission, Reihe B, vol 313, München

Behrend D, Cucurull L, Vila J, Haas R (2000) An inter-comparison study to estimate zenith wet delays using VLBI, GPS and NWP models. Earth Planets Space 52(10):691-694

Berg H (1948) Allgemeine Meteorologie. Dümmlers Verlag, Bonn

Beutler G, Rothacher M, Schaer S, Springer T, Kouba J, Neilan R (1999) The International GPS Service (IGS): an interdisciplinary service in support of Earth sciences. Advances in Space Research 23(4):631-653

Boehm J, Schuh H, Weber R (2001) Comparison of tropospheric gradients determined by VLBI and GPS. Phys Chem Earth 26(68):385-388, DOI 10.1016/S1464-1895(01)00070-9

Boehm J, Schuh H, Tesmer V, Schmitz-Huebsch H (2003) Tropospheric zenith delays determined by VLBI as a contribution to climatological studies. In: Schwegmann W, Thorandt V (eds) Proceedings of the 16th Working Meeting on European VLBI for Geodesy and Astrometry, Bundesamt für Kartographie und Geodäsie, Leipzig/Frankfurt am Main, pp 237-246

Boucher C, Altamimi Z, Sillard P (1998) Results and analysis of the ITRF96. IERS Tech. Note, vol 24, Obs. de Paris, Paris

Boucher C, Altamimi Z, Sillard P (1999) The 1997 International Terrestrial Reference Frame (ITRF97). IERS Tech. Note, vol 27, Obs. de Paris, Paris

Chen G, Herring T (1997) Effects of atmospheric azimuthal asymmetry on the analysis of space geodetic data. J Geophys Res 102(B9):20,489-20,502

Dong D, Fang P, Bock Y, Cheng M, Miyazaki S (2002) Anatomy of apparent seasonal variations from GPS-derived site position time series. J Geophys Res 107(B4), DOI 10.1029/2001JB000573

Gendt G (1996) Comparison of IGS troposphere estimations. In: Neilan RE, van Scoy PA, Zumberge JF (eds) Proceedings IGS 1996 Analysis Center Workshop, IGS Central Bureau, Pasadena, pp 151-164

Gradinarsky L, Haas R, Elgered G, Johansson J (2000) Wet path delay and delay gradients inferred from microwave radiometer, GPS and VLBI observations. Earth Planets Space 52(10):695-698

Gradinarsky L, Johansson J, Bouma H, Scherneck HG, Elgered G (2002) Climate monitoring using GPS. Phys Chem Earth 27(45):335-340, DOI 10.1016/S1474-7065(02)00009-8

Haas R, Elgered G, Gradinarsky L, Johansson J (2003) Assessing long term trends in the atmospheric water vapor content by combining data from VLBI, GPS, radiosondes and microwave radiometry. In: Schwegmann W, Thorandt V (eds) Proceedings of the 16th Working Meeting on European VLBI for Geodesy and Astrometry, Bundesamt für Kartographie und Geodäsie, Leipzig/Frankfurt am Main, pp 279-288

Hugentobler U, Dach R, Fridez P, Meindl M (eds) (2006) Bernese GPS Software Version 5.0. Astronomical Institute, University of Bern, draft version available at http://www.bernese.unibe.ch/docs/DOCU50draft.pdf

Krügel M, Tesmer V, Angermann D, Thaller D, Rothacher M, Schmid R (2004) CONT02 campaign - combination of VLBI and GPS. In: Vandenberg NR, Baver KD (eds) International VLBI Service for Geodesy and Astrometry 2004 General Meeting Proceedings, NASA/CP-2004-212255, NASA, Greenbelt, pp 418-422

MacMillan D (1995) Atmospheric gradients from very long baseline interferometry observations. Geophysical Research Letters 22(9):1041-1044

Meindl M, Schaer S, Hugentobler U, Beutler G (2004) Tropospheric gradient estimation at CODE: Results from global solutions. Journal of the Meteorological Society of Japan 82(1B):331-338

Menge F, Seeber G, Völksen C, Wübbena G, Schmitz M (1998) Results of absolute field calibration of GPS antenna PCV. In: Proceedings of ION GPS-98, Nashville, Sept, pp 31-38

Miller A (1976) The climate of Chile. In: Schwerdtfeger W (ed) Climates of Central and South America, World Survey of Climatology, vol 12, Elsevier, Amsterdam-Oxford-New York, pp 113-145

Niell A (1996) Global mapping functions for the atmosphere delay at radio wavelengths. J Geophys Res 101(B2):3227-3246

Niell A, Coster A, Solheim F, Menders V, Toor P, Langley R, Upham C (2001) Comparison of measurements of atmospheric wet delay by radiosonde, water vapor radiometer, GPS, and VLBI. Journal of Atmospheric and Oceanic Technology 18(6):830-850

Pacione R, Fionda E, Ferrara R, Lanotte R, Sciarretta C, Vespe F (2002) Comparison of atmospheric parameters derived from GPS, VLBI and a ground-based microwave radiometer in Italy. Phys Chem Earth 27(4-5):309-316, DOI 10.1016/S14747065(02)00005-0

Rothacher M (2002) Estimation of station heights with GPS. In: Drewes H, Dodson A, Fortes L, Sanchez L, Sandoval P (eds) Vertical Reference Systems, Springer, Berlin Heidelberg New York, International Association of Geodesy Symposia, vol 124, pp 81-90

Rothacher M, Ma C (2006) Steps toward a future set of IERS products and a modified IERS structure. In: Richter B, Dick W (eds) Proceedings of the IERS Workshop on Combination, Bundesamt für Kartographie und Geodäsie, in press

Saastamoinen J (1973) Contributions to the theory of atmospheric refraction. Bull Géod 107:13-34

Schlüter W, Himwich E, Nothnagel A, Vandenberg N, Whitney A (2002) IVS and its important role in the maintenance of the global reference systems. Advances in Space Research 30(2):145-150, DOI 10.1016/S0273-1177(02)00278-8

Schmid R, Rothacher M (2003) Estimation of elevation-dependent satellite antenna phase center variations of GPS satellites. J Geod 77(7-8):440-446, DOI 10.1007/s00190-003-0339-0 
Schmid R, Rothacher M, Thaller D, Steigenberger P (2005) Absolute phase center corrections of satellite and receiver antennas: Impact on global GPS solutions and estimation of azimuthal phase center variations of the satellite antenna. GPS Sol 9(4):283-293, DOI 10.1007/s10291-005-0134-x

Schmid R, Steigenberger P, Gendt G, Ge M, Rothacher M (2006) Generation of a consistent absolute phase center correction model for GPS receiver and satellite antennas. J Geod Submitted

Snajdrova K, Boehm J, Willis P, Haas R, Schuh H (2005) Multi-technique comparison of tropospheric zenith delays derived during the CONT02 campaign. J Geod 79(10-11):613-623, DOI 10.1007/s00190-005-0010-z

Steigenberger P, Rothacher M, Dietrich R, Fritsche M, Rülke A, Vey S (2006) Reprocessing of a global GPS network. J Geophys Res 111(B05402), DOI 10.1029/2005JB003747

Tesmer V, Kutterer H (2004) An advanced stochastic model for VLBI observations and its application to VLBI data analysis. In: Vandenberg NR, Baver KD (eds) International VLBI Service for Geodesy and Astrometry 2004 General Meeting Proceedings, NASA/CP-2004-212255, NASA, Greenbelt, pp 296-300

Tesmer V, Kutterer H, Drewes H (2004) Simultaneous estimation of a TRF, the EOP and a CRF. In: Vandenberg NR, Baver KD (eds) International VLBI Service for Geodesy and Astrometry 2004 General Meeting Proceedings, NASA/CP-2004-212255, NASA, Greenbelt, pp 311-314

Thaller D, Dill R, Krügel M, Steigenberger P, Rothacher M, Tesmer V (2006) CONT02 analysis and combination of long EOP series. In: Flury J, Rummel R, Reigber C, Rothacher M, Boedecker G, Schreiber U (eds) Observation of the Earth system from space, Springer, Berlin Heidelberg New York, pp 389-411

Thomas C, MacMillan D (2003) Core operation center report. In: Vandenberg NR, Baver KD (eds) International VLBI Service for Geodesy and Astrometry 2002 Annual Report, NASA/TP-2003211619, Goddard Space Flight Center, Maryland, pp 179-181

Titov O, Tesmer V, Boehm J (2004) Occam v6.0 software for VLBI data analysis. In: Vandenberg NR, Baver KD (eds) International VLBI Service for Geodesy and Astrometry 2004 General Meeting Proceedings, NASA/CP-2004-212255, NASA, Greenbelt, pp 267-271 